\title{
Alginate rafts localize to the acid pocket and reduce acid reflux in GERD
}

"The acid pocket has recently been identified as the reservoir from which reflux of gastric contents into the oesophagus occurs," says Guy Boeckxstaens from the Translational Research Center for Gastrointestinal Disorders (TARGID), Leuven, Belgium. Boeckxstaens and his co-workers wanted to investigate whether the therapeutic effect of alginates-polysaccharide polymers that form a floating raft of viscous gel on top of gastric contentsmight be explained by their interaction with the acid pocket.

The researchers enrolled 16 patients with symptomatic GERD. After a standard meal, eight received radioactively labelled alginate-antacid and the other eight received antacid. This labelling technique enabled the location of the alginate-antacid to be visualized by scintigraphy for up to $2 \mathrm{~h}$. Reflux episodes were also measured using simultaneous high-resolution manometry and $\mathrm{pH}$-impedance recording.
The main finding from this study was that the alginate-antacid raft did indeed localize to the acid pocket. Furthermore, the alginate-antacid raft seemed to displace the acid pocket below the diaphragm in $71 \%$ of reflux episodes, compared with in $21 \%$ of reflux episodes in patients who received antacid. The number of acid reflux episodes was significantly lower $(P=0.03)$, and the time to reflux was significantly higher $(P=0.01)$, in patients receiving the alginate-antacid preparation than those who received the antacid alone. The researchers suggest that displacement of the acid pocket by the alginate raft is also responsible for a shift from acidic to weakly acidic reflux events.

Alginates have been used in the treatment of reflux for decades. "This work significantly contributes to our understanding of the mechanism of action of alginates and further demonstrates that the acid pocket might indeed represent an interesting target for treatment of reflux disease," says Boeckxstaens.

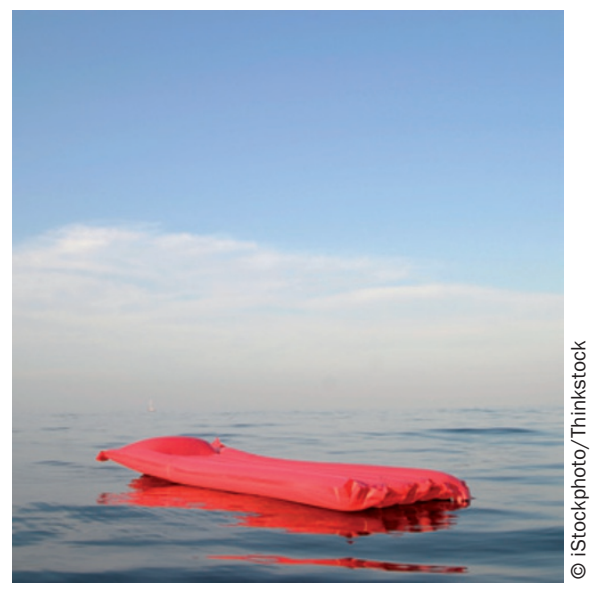

The researchers are also interested in whether alginates might be useful in the treatment of patients with GERD who have symptoms that are resistant to PPIs. Alginates could not only be effective as monotherapy, therefore, but also as add-on therapy in these patients with complicated GERD.

\section{Isobel Leake}

Original article Rohof, W. O. et al. An alginate-antacid formulation localizes to the acid pocket to reduce acid reflux in patients with gastroesophageal reflux disease. Clin. Gastroenterol. Hepatol. doi:10.1016/j.cgh.2013.04.046 